\title{
Early Treatment with Basal Insulin Glargine in People with Type 2 Diabetes: Lessons from ORIGIN and Other Cardiovascular Trials
}

\author{
Markolf Hanefeld · Louis Monnier · Oliver Schnell · David Owens
}

To view enhanced content go to www.diabetestherapy-open.com Received: November 10, 2015 / Published online: February 10, 2016

(C) The Author(s) 2016. This article is published with open access at Springerlink.com

\section{ABSTRACT}

Dysglycemia results from a deficit in first-phase insulin secretion compounded by increased insulin insensitivity, exposing $\beta$ cells to chronic hyperglycemia and excessive glycemic variability. Initiation of intensive insulin therapy at diagnosis of type 2 diabetes mellitus (T2DM) to achieve normoglycemia has been shown to reverse glucotoxicity, resulting in recovery of residual $\beta$-cell function. The United Kingdom Prospective Diabetes Study

Electronic supplementary material The online version of this article (doi:10.1007/s13300-016-0153-3) contains supplementary material, which is available to authorized users.

M. Hanefeld

Study Centre Professor Hanefeld, GWT-TUD GmbH, Dresden, Germany

\section{Monnier}

Institute of Clinical Research, University

Montpellier 1, Montpellier, France

O. Schnell

Ludwig-Maximilians-University, Munich, Germany

D. Owens $(\bowtie)$

Institute of Life Sciences, Swansea University,

Swansea, UK

e-mail: owensdr@cardiff.ac.uk; owensdr@cf.ac.uk
(UKPDS) 10-year post-trial follow-up reported reductions in cardiovascular outcomes and all-cause mortality in persons with T2DM who initially received intensive glucose control compared with standard therapy. In the cardiovascular outcome trial, outcome reduction with an initial glargine intervention (ORIGIN), a neutral effect on cardiovascular disease was observed in the population comprising prediabetes and T2DM. Worsening of glycemic control was prevented over the 6.7 year treatment period, with few serious hypoglycemic episodes and only moderate weight gain, with a lesser need for dual or triple oral treatment versus standard care. Several other studies have also highlighted the benefits of early insulin initiation as first-line or add-on therapy to metformin. The decision to introduce basal insulin to metformin must, however be individualized based on a risk-benefit analysis. The landmark ORIGIN trial provides many lessons relating to the concept and application of early insulin therapy for the prevention and safe and effective induction and maintenance of glycemic control in type 2 diabetes.

Funding: Sanofi. 
Keywords: $\beta$-Cell function; Dysglycemia; Insulin glargine; ORIGIN study; Patient-centered treatment

\section{INTRODUCTION}

Over the last few decades, there has been a dramatic global increase in the number of people with pre-diabetes [characterized by either impaired fasting glucose (IFG) or impaired glucose tolerance (IGT)] and known type 2 diabetes mellitus (T2DM). Dysglycemia is associated with multiple diabetes-related complications, cardiovascular disease (CVD), and premature death [1, 2]. A person with T2DM is two- to four-times more likely to develop CVD, the major cause of death in diabetes [1]. Morbidity associated with microvascular complications (retinopathy, nephropathy, and neuropathy) also represents a major burden in T2DM [3-7]. Consequently, dysglycemia has become a serious economic burden and is one of today's most important public health challenges $[1,2]$.

Although intervention in IGT involving lifestyle change [8], metformin [9], or acarbose [10] reduces the incidence of T2DM, the effects are not always sustained. Similar results were seen in people with newly diagnosed type 2 diabetes in the United Kingdom Prospective Diabetes Study (UKPDS) [3] and in A Diabetes Outcome Progression Trial (ADOPT) [11]. Rosiglitazone, but neither glibenclamide nor metformin, had a long-lasting effect on preventing diabetes progression [11]. However, together with lifestyle intervention, metformin is still recommended as first-line therapy in international guidelines [12] based on findings in the UKPDS involving a relatively small number of obese subjects who had a favorable cardiovascular (CV) outcome on metformin [3].
In obese people with IFG, autopsy studies reveal that more than $40 \%$ of the $\beta$-cell mass had already been lost, while in obese and lean people with T2DM $\beta$-cell mass was reduced by $63 \%$ and $41 \%$, respectively $[13,14]$. This is in keeping with the $50 \%$ loss of $\beta$-cell function when patients first present with T2DM [15]. The deficit in $\beta$-cell function develops along a continuum of hyperglycemia, starting below the cutoff limits for the diagnosis of pre-diabetes and overt diabetes [16]. Because $\beta$-cell loss and impaired insulin secretion play a central role in the progression of dysglycemia from pre-diabetes to frank diabetes, a critical appraisal of our current therapeutic management paradigm seems appropriate at this time. Therefore, the key intent of this article is to address and analyze the rationale, efficacy, safety and practicability of early insulin therapy in people with T2DM. Central to the discussion will be the use of basal insulin glargine, which has recently been investigated in the large-scale and long-term outcome reduction with an initial glargine intervention (ORIGIN) trial (ClinicalTrials.gov NCT00069784) [17] and followed by a post-trial study of the ORIGIN and Legacy Effects (ORIGINALE) study of the earlier interventions [18].

\section{PATHOPHYSIOLOGY OF GLUCOSE REGULATION: A KEY ARGUMENT FOR EARLY INSULIN USE}

In people with normal glucose tolerance, there is a competent time-related quantitative and qualitative $\beta$-cell response to the carbohydrate milieu (Fig. S1). In people with dysglycemia and diabetes, continuous glucose measurement reveals a progressive deterioration of glucose homeostasis that has harmful effects on both $\beta$ 
cells and the endothelium (Fig. S2a) [16, 19, 20]. The underlying pathophysiology in the early phase of glucose intolerance is a loss of pulsatile insulin secretion and a deficit in acute insulin response to a nutrient load (Fig. S2b) [21, 22]. During this early phase there is a dramatic increase in insulin resistance, along with inappropriate hyper-glucagonemia resulting in excessive hepatic gluconeogenesis [21]. These three factors-insulin deficit, enhanced glucagon response, and insulin resistanceinteract in a vicious cycle, resulting in a state of glucotoxicity and lipotoxicity (gluco-lipo-toxicity) as driving forces for the progressive loss of $\beta$-cell secretory capacity and mass [23], along with the impact of inflammation and the presence of cytokines and amyloid [24]. With an early insulin deficit playing such a key role, the question arises as to whether near to normal control of fasting plasma glucose (FPG), and/or postprandial glucose (PPG), and/or glucose variability can prevent or reverse this vicious cycle early in the natural history of abnormal glucose tolerance.

\section{IMPACT OF HYPERGLYCEMIA AND HYPERLIPIDEMIA: THE CASE FOR EARLY INSULIN USE}

In vitro experiments have shown that long-lasting hyperglycemia results in diminished insulin gene expression in $\beta$ cells $[21,25]$. These glucotoxic effects are reversible with euglycemic conditions, and the shorter the exposure to hyperglycemia, the greater the degree of $\beta$ cell recovery $[23,26]$. In addition, hypertriglyceridemia results in significant triglyceride stores in the islets, with a negative impact on $\beta$-cell function [27]. Thus, both glucotoxic and lipotoxic environments have a deleterious effect on $\beta$-cell function.
Insulin lowers plasma free fatty acids through its inhibition of lipolysis, while it also corrects other features of atherogenic diabetic dyslipidemia such as increasing high density lipoprotein-cholesterol and lowering triglycerides [25]. Better control of PPG with a short-acting insulin secretagogue or insulin analog was associated with increased myocardial blood flow in patients with T2DM [28]. A short-acting sulfonylurea has also been shown to reduce carotid intima thickness (CIT) in patients with T2DM, which was associated with changes in PPG in contrast to a longer-acting sulfonylurea, which had an impact primarily on the FPG levels [29]. Early intensive insulin therapy in people who were newly diagnosed with T2DM has been shown to reduce the inflammatory marker tumor necrosis factor alpha and improve endothelial function [30-33]. These findings suggest that insulin has pleiotropic effects on putative $\mathrm{CV}$ risk factors and endothelial dysfunction.

Exposure to hyperglycemia at the onset of diabetes initiates a vicious legacy of 'metabolic memory' [34]. The overproduction of reactive oxygen species (ROS) by the mitochondrial electron transport chain is the underlying mechanism of glucose- and lipid-mediated vascular damage in diabetes facilitated by excess production of sorbitol, advanced glycation end-products (AGE), increased hexosamine flux and protein kinase C (Fig. 1) [34-36]. AGE modification of mitochondrial DNA respiratory proteins results in excess ROS production and cellular damage. These, along with the increased production of peroxynitrite, create endothelial damage that results in excess CVD. Similarly, $\beta$ cells exposed to a higher level of ROS result in $\beta$-cell dysfunction and increased $\beta$-cell apoptosis $[13,37,38]$. These mechanistic studies suggest that insulin 


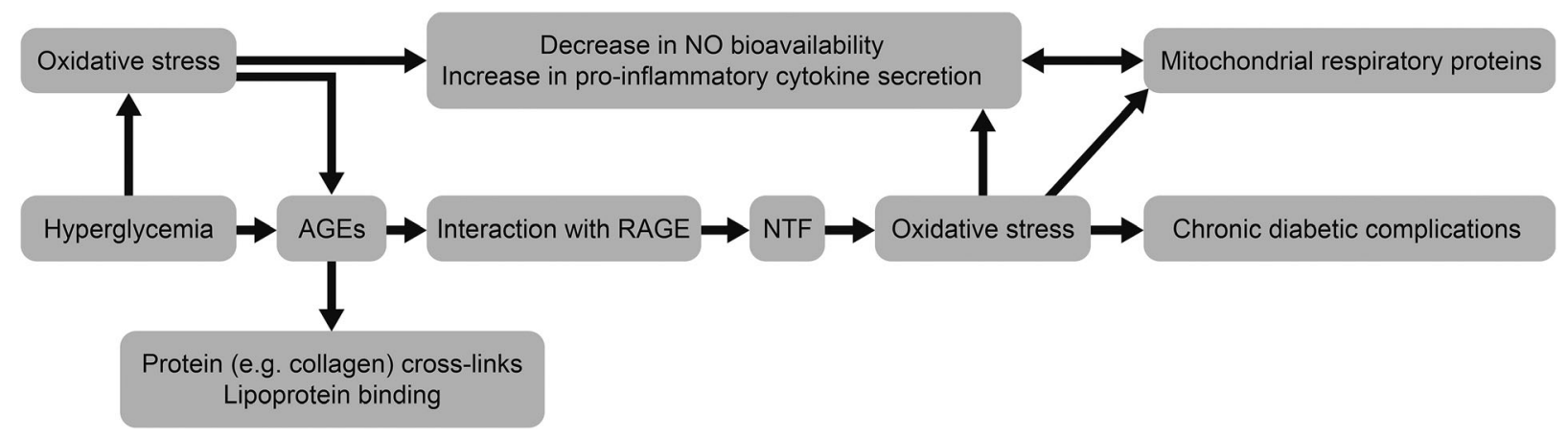

Fig. 1 The vicious circle of 'metabolic memory' [36]. AGEs advanced glycation end-products, $N O$ nitric oxide, $N T F$ neurotrophic factor, $R A G E$ receptor for advanced glycation end-product. Reproduced with permission from Drzewoski

treatment introduced early following diagnosis to lower blood glucose to normoglycemia will effectively abolish gluco-lipo-toxicity and thereby restore residual $\beta$-cell function and reduce apoptosis [39]. Among the available anti-diabetic drugs, only insulin allows rapid and consistent near to normal glucose control within a few days-even with glycated hemoglobin $\left(\mathrm{HbA}_{1 \mathrm{c}}\right)$ levels $>9 \%$ at diagnosis [40-42].

\section{BENEFITS OF EARLY INSULIN REPLACEMENT ON B-CELL FUNCTION}

The beneficial effect of early glycemic control on $\beta$-cell function has been demonstrated in several studies (Table S1) [41-51]. One of the largest studies was conducted in China and involved 382 persons with newly diagnosed type 2 diabetes randomized to insulin therapy, via either continuous subcutaneous insulin infusion or multiple daily injections, or oral hypoglycemic agents [41]. When normoglycemia was achieved, treatment was stopped and the remission rates at 1 year were $51.1 \%, 44.9 \%$ and $26.7 \%$, respectively. Chen
J, Kasznicki J, Trojanowski Z. The role of "metabolic memory" in the natural history of diabetes mellitus. Pol Arch Med Wewn. 2009;119:493-500

et al. treated people with newly diagnosed T2DM who had been hospitalized with severe hyperglycemia with short-term intensive insulin therapy followed by 6 months of insulin therapy or oral anti-diabetic drugs [43]. The improved $\beta$-cell function was better maintained with insulin therapy than with oral drugs. In 2009, Xu et al. published long-term follow-up results on the remission of hyperglycemia and improved $\beta$-cell function following intensive insulin treatment in people with newly diagnosed T2DM with an $\mathrm{HbA}_{1 \mathrm{c}}$ of $9.9 \pm 2.2 \%$ at baseline [52]. After 2 years, approximately $50 \%$ of those who completed the study remained near-normoglycemic with sustained improvement in $\beta$-cell function. Remission was seen to occur more frequently in subjects with a shorter diabetes duration and better glucose control during intensive insulin treatment $[29,52]$. In a retrospective analysis of a large cohort of newly diagnosed persons with T2DM, Chon et al. demonstrated that early insulin treatment leads to a long-lasting improvement in $\beta$-cell function that facilitates long-term glycemic control, compared with the use of oral anti-diabetic drugs as first-line therapy. The positive results observed over the 
4-year study duration occurred irrespective of the method of insulin delivery [53]. Harrison et al. showed that the improvement in $\beta$-cell function obtained with 3 months of intensive insulin therapy plus metformin in newly diagnosed patients with T2DM could be preserved for at least 3.5 years with insulin plus metformin or triple oral therapy [45]. In a comparative study with drug-naïve patients with T2DM, basal insulin glargine administered as first-line treatment induced a significantly better recovery of $\beta$-cell function (proinsulin/C-peptide ratio and homeostasis model assessment B) than metformin, despite both being equally effective at controlling $\mathrm{HbA}_{1 \mathrm{c}}$ in the target range [50]. Zeng et al. also reported an improvement in $\beta$-cell function with basal insulin glargine in newly diagnosed patients with T2DM [54].

Few studies have compared different insulin preparations with respect to $\beta$-cell protection. Insulin glargine is as effective as neutral protamine Hagedorn (NPH) insulin at controlling $\mathrm{HbA}_{1 \mathrm{c}}$ levels, but is associated with a lower risk of hypoglycemia [55] owing to its flatter and longer-lasting pharmacodynamic profile and therefore has the advantage of causing less glycemic variability. Adding insulin glargine versus NPH to metformin resulted in a more efficient reduction in $\beta$-cell stress in the glargine group. Although FPG and PPG levels did not differ between the two treatments, glargine reduced intact pro-insulin significantly more after lunch and dinner than did NPH [56].

These studies all suggest that early intensive insulin therapy allows the pancreas to rest by reducing $\beta$-cell stress, which leads to an improvement in $\beta$-cell function. A short course of intensive insulin therapy also results in significant improvements in quality of life and treatment satisfaction [57].

\section{EARLY INTRODUCTION OF BASAL INSULIN ADDED TO ORAL ANTI-DIABETIC TREATMENT}

Recommendations from the new patient-centered joint position statement of leading experts from the American Diabetes Association (ADA) and the European Association for the Study of Diabetes (EASD) suggest six options as second-line therapy if maximally tolerated doses of metformin fail to sufficiently control $\mathrm{HbA}_{1 \mathrm{c}}$ : i.e., a sulfonylurea, pioglitazone, sodium glucose co-transporter 2 inhibitors, dipeptidyl peptidase- 4 inhibitors, glucagon-like peptide-1 (GLP-1) analogs, and basal insulin [12]. However, in practice, insulin tends to be used only if dual or triple therapy at maximal doses of combined oral anti-diabetic drugs or GLP-1 analogs fail to achieve an $\mathrm{HbA}_{1 \mathrm{c}}$ of $<7-7.5 \%$, resulting in an unfortunate delay in achieving good glycemic control.

The efficacy and safety of early basal insulin in type 2 diabetes (EARLY) trial was a non-interventional observational study evaluating the efficacy and safety of insulin glargine under real-world conditions in 1438 people with T2DM insufficiently controlled with maximally tolerated doses of metformin [58]. Insulin glargine was titrated to a target FPG of $\leq 5.6 \mathrm{mmol} / \mathrm{L}$ resulting in a significant decrease in $\mathrm{HbA}_{1 \mathrm{c}}$ from $8.7 \%$ at baseline to $7.4 \%$ after 6 months $[58,59]$. The decrease in $\mathrm{HbA}_{1 \mathrm{c}}$ was significantly greater for people with diabetes duration of $<5$ years and for those with a lower $\mathrm{HbA}_{1 \mathrm{c}}$ and body mass index at baseline. Only $2.5 \%$ of patients reported hypoglycemic events and seven patients had severe hypoglycemia thus the early use of insulin glargine in these patients was seen to be effective and well tolerated.

These findings are in accord with the analysis of clinical trials by Fonseca et al. where more 
subjects were found to have achieved $\mathrm{HbA}_{1 \mathrm{c}}$ $\leq 7 \%$ on metformin and insulin glargine (early insulin initiation), with the least weight gain and risk of hypoglycemia despite a higher insulin dose than those who were on comparator therapies (later insulin initiation). This supports the inclusion of basal insulin as a rational second step in the treatment algorithm for T2DM [60]. Pennartz et al. achieved a sustained reduction of FPG to a target of $5.6 \mathrm{mmol} / \mathrm{L}$ with insulin glargine in subjects failing on metformin therapy, which resulted in an improvement in both the first- and second-phase insulin secretion, supporting the concept of pancreatic rest as a result of near normal fasting plasma glucose [61].

However, an individualized patient-centered decision is required, owing to the ever increasing options now available as add-on therapy to metformin.

\section{LONG-TERM IMPACT OF INTENSIVE GLUCOSE CONTROL ON CV OUTCOMES}

Recently, observational trials have highlighted that CVD remains the major cause of morbidity and mortality in people with abnormal glucose tolerance and T2DM $[62,63]$. A meta-analysis of mega-trials with $\mathrm{CV}$ outcomes as the primary objective showed that intensive glucose control in those with long-term diabetes resulted in a small but significant reduction in non-fatal myocardial infarction (MI, odds ratio 0.83), but it did not reduce the risk of all-cause mortality or death due to $\mathrm{CV}$ or cerebrovascular disease [64-66]. The first controlled trial to report a significant benefit of intensified glucose control on macrovascular complications and all-cause mortality was the Diabetes Intervention Study (DIS), the only outcome study that specifically controlled for (1-h) PPG in newly diagnosed people with T2DM [67].

The UKPDS legacy evaluation, a 10-year post-trial follow-up study of people with T2DM receiving intensive glucose control with insulin compared with conventional therapy, resulted in the emergence of a significant reduction in $\mathrm{CV}$ outcomes and all-cause mortality [6]. This effect was observed despite between-group differences in $\mathrm{HbA}_{1 \mathrm{c}}$ being lost after the first year post-trial. The authors concluded that early intensive glucose control, initiated as soon as diabetes has been diagnosed, is an effective tool to prevent $\mathrm{CV}$ complications over the long term [6]. The Epidemiology of Diabetes Interventions and Complications (EDIC) study [68], the long-term follow-up study of the Diabetes Control and Complications Trial (DCCT), demonstrated a similar emergence of $\mathrm{CV}$ benefits over a mean 17-year follow-up period in people with type 1 diabetes [69]. CV benefits were also seen with intensive and goal-oriented polypharmacy treatment of known modifiable risk factors in high-risk people with T2DM [44, 70]. Thus, early intervention to keep blood glucose and $\mathrm{HbA}_{1 \mathrm{c}}$ in the near to normal range seems to be the key to reducing CV morbidity and mortality. Although intensive glucose control results in significant effects on retinopathy and nephropathy within a shorter period of time (5-10 years), significant improvements in the primary prevention of CVD have only been reported after a longer period of follow-up [44, 59, 67, 69, 70].

\section{ORIGIN}

A landmark study in people with T2DM and a high CV risk profile, ORIGIN was a 
multinational, multicenter, randomized, controlled trial of 12,537 people with dysglycemia including pre-diabetes and type 2 diabetes, which was designed to evaluate the effects of insulin glargine or omega-3 fatty acids (polyunsaturated fatty acids) on CV outcomes in a high-risk population. CV risk was defined as prior major $\mathrm{CV}$ events/disease or multiple $\mathrm{CV}$ risk factors [71]. Table 1 highlights the differences between ORIGIN and the mega-trials Action to Control Cardiovascular Risk in Diabetes (ACCORD) [5], Action in Diabetes and Vascular Disease: Preterax and Diamicron Modified Release Controlled Evaluation (ADVANCE) [7], and the Veterans Affairs Diabetes Trial (VADT) [4]. Among the differences were more macrovascular complications, shorter diabetes duration, and lower $\mathrm{HbA}_{1 \mathrm{c}}$ levels at randomization in the ORIGIN trial population. Also, $82 \%$ of the ORIGIN participants had early T2DM (on 0 or
1 oral anti-diabetic drug), 6\% had newly detected T2DM, and the remaining 12\% had pre-diabetes (IFG and/or IGT), highlighting that insulin glargine intervention was being introduced early in the course of the disease. In addition, glargine was titrated to reach an FPG level of $\leq 5.3 \mathrm{mmol} / \mathrm{L}$ [71]. In the standard care group, $5 \%$ were treated with prandial insulin, 11\% were treated with a basal insulin, and nearly twice as many patients were treated with sulfonylurea. There were two co-primary outcomes, which were first the composite endpoint of non-fatal MI, non-fatal stroke, or CV death; and secondly the composite endpoint of non-fatal MI, non-fatal stroke, CV death, revascularization procedure, or hospitalization for heart failure. ORIGIN was a treat-to-target trial; however, a very conservative titration algorithm was developed because insulin glargine was initiated at such an early stage of glucose intolerance. After a

Table 1 Baseline characteristics in ORIGIN and other cardiovascular outcome studies

\begin{tabular}{|c|c|c|c|c|}
\hline & ACCORD & VADT & ADVANCE & ORIGIN \\
\hline$N$ & 10,251 & 1791 & 11,140 & 12,537 \\
\hline Age (years) & 62 & 60 & 66 & 64 \\
\hline Diabetes (years) & $10^{\mathrm{a}}$ & $11.5^{\mathrm{b}}$ & $8^{b}$ & $5^{b}$ \\
\hline IFG/IGT (\%) & 0 & 0 & 0 & 12 \\
\hline Macrovascular complications (\%) & 35 & 40 & 32 & 59 \\
\hline Baseline $\mathrm{HbA}_{1 \mathrm{c}}(\%)$ & $8.1^{\mathrm{a}}$ & $9.4^{\mathrm{b}}$ & $7.5^{\mathrm{b}}$ & $6.4^{\mathrm{b}}$ \\
\hline Treatment target & $\mathrm{HbA}_{1 \mathrm{c}}<6 \%^{\mathrm{c}}$ & $\mathrm{HbA}_{1 \mathrm{c}}<6 \%{ }^{\mathrm{c}}$ & $\mathrm{HbA}_{1 \mathrm{c}} \leq 6.5 \%^{\mathrm{c}}$ & $\mathrm{FPG} \leq 5.3 \mathrm{mmol} / \mathrm{L}$ \\
\hline Intervention & Multiple drugs & Multiple drugs & Glicazide \pm others & Glargine \pm others \\
\hline
\end{tabular}

ACCORD Action to Control Cardiovascular Risk in Diabetes, ADVANCE Action in Diabetes and Vascular Disease: Preterax and Diamicron Modified Release Controlled Evaluation, FPG fasting plasma glucose, IFG impaired fasting glucose, $I G T$ impaired glucose tolerance, $H b A_{1 c}$ glycated hemoglobin, ORIGIN Outcome Reduction With an Initial Glargine Intervention, $V A D T$ Veterans Affairs Diabetes Trial

${ }^{a}$ Median

b Mean

c Intensive group

d $\leq 95 \mathrm{mg} / \mathrm{dL}(1 \mathrm{mmol} / \mathrm{L}=18 \mathrm{mg} / \mathrm{dL})$ 
median follow-up of 6.2 years and a final dosage of 0.4 units $/ \mathrm{kg}$ of insulin glargine (approximately 28 units once per day), CV outcomes were similar in both treatment arms: 2.94 vs. 2.85 events per 100 person-years in the insulin glargine and standard care groups, respectively [17]. Administration of insulin glargine to patients with a history of prior $\mathrm{CV}$ events was not associated with a higher incidence of the primary outcome [hazard ratio (HR) 0.97 (95\% confidence interval (CI) 0.87-1.07)]. These data indicated that basal insulin treatment in the form of insulin glargine was safe in persons with type 2 diabetes with pre-existing $\mathrm{CV}$ events. This finding was in contrast with the Euro Heart Survey on Diabetes and the Heart [72] and the Diabetes Mellitus Insulin-Glucose Infusion in Acute Myocardial Infarction 2 (DIGAMI 2) study [73], which suggested that insulin intervention was associated with a higher risk of a CV event after acute coronary syndrome.

Overall, ORIGIN demonstrated that insulin glargine had a neutral effect on CV outcomes and was associated with no increased risk for serious $\mathrm{CV}$ events in people with pre-existing $\mathrm{CV}$ risk. In the Glucose Reduction and Atherosclerosis Continuing Evaluation (GRACE) sub-study of ORIGIN, which included 1184 patients with carotid ultrasound at baseline, the impact of insulin glargine treatment on CIT was specifically evaluated [74]. Over a median of 4.9 years, a non-significant reduction in CIT was demonstrated with glargine compared with standard care. The decrease in CIT, however, was consistent with that observed in DCCT/ EDIC, in which the benefits of improved glucose control were observed after long-term follow-up [73].

A secondary analysis of ORIGIN evaluated the attainment and maintenance of $\mathrm{HbA}_{1 \mathrm{c}}$ below target of 7\% [75]. Both strategies maintained the mean $\mathrm{HbA}_{1 \mathrm{c}}$ levels of 6.0 to $<6.6 \%$ for 5 years, i.e., $6.3 \%$ (range $5.8-6.9 \%$ ) with insulin glargine versus $6.6 \%$ (range $6.1-7.3 \%)$ with standard care. A total of $77 \%$ of patients in the glargine arm versus $66 \%$ of those in the standard care arm attained an $\mathrm{HbA}_{1 \mathrm{c}}$ of $<7 \%$ after 5 years. Those participants in the insulin glargine arm needed fewer dual and triple combinations and complex insulin regimens compared with those receiving standard care $(14 \%$ vs. $42 \%$, respectively). Rates of adverse events (e.g., severe hypoglycemia) with insulin glargine were low compared with those in previous outcome trials in people with advanced diabetes; however, the patient populations in these trials were not the same.

Analysis of the frequency and complications of severe hypoglycemia in ORIGIN has shown that although the incidence of severe hypoglycemia was higher with insulin, CV complications and mortality were two to three times higher when associated with severe hypoglycemia and standard care [75, 76]. In addition intervention with insulin glargine reduced the incidence of diabetes among those with pre-diabetes at randomization, despite weight gain [17], which prevailed in the 2.7-year post-ORIGIN study [18].

Continuous subcutaneous glucose measurements in patients receiving insulin glargine treatment during ORIGIN showed a stable circadian glucose profile with an $\mathrm{HbA}_{1 \mathrm{c}}$ of $5.7 \pm 0.4 \%$. A low rate of nocturnal hypoglycemic episodes after 2 years was also observed. Glycemic variability when measured by the mean amplitude of glycemic excursions (MAGE) in the insulin glargine group was $2.47 \pm 1.1 \quad$ vs. $\quad 2.56 \pm 1.28 \mathrm{mmol} / \mathrm{L}$ with standard care [77]. ORIGIN also demonstrated that early insulin glargine treatment resulted in 
only a moderate weight gain of $1.6 \mathrm{~kg}$ after 6 years [17]. In comparison, weight gain in ACCORD and VADT was 3.5 and $4.0 \mathrm{~kg}$, respectively $[4,5]$. In the Treating to Target in Type 2 Diabetes (4-T) study, in which participants received complex insulin regimens, the weight increase from baseline was $5.7 \mathrm{~kg}$ in the biphasic insulin aspart group and $6.4 \mathrm{~kg}$ in the prandial insulin aspart group, compared to $3.6 \mathrm{~kg}$ in the basal insulin (insulin detemir) treated group [42, 78].

Insulin glargine reduced the incidence of the composite outcome of kidney and eye disease in patients from ORIGIN with a baseline $\mathrm{HbA}_{1 \mathrm{c}}$ $\geq 6.4 \%$ [HR 0.90 (95\% CI 0.81-0.99)] compared with standard care, but not in those participants with a baseline $\mathrm{HbA}_{1 \mathrm{c}}<6.4 \%$ [HR 1.07 (95\% CI 0.90-1.20)] [79]. ORIGIN also demonstrated that treatment with glargine for $>6$ years was not associated with an increased risk of cancer and cancer mortality compared with standard care [71]. In a follow-up sub-study of ORIGIN, it was demonstrated that achieving a target of fasting plasma glucose $<5.3 \mathrm{mmol} / \mathrm{L}$ with insulin glargine resulted in a near normal postprandial glucose excursion [77].

\section{CONCLUSIONS}

ORIGIN provides a relatively long-term study in persons with pre-diabetes and type 2 diabetes who have a high CV risk profile early in the course of their disease. Previously, diabetes prevention trials including Nateglinide And Valsartan in Impaired Glucose Tolerance Outcomes Research (NAVIGATOR) [80, 81], involved persons with type 2 diabetes at moderate $\mathrm{CV}$ risk whereas in the Diabetes Prevention Program (DPP) [9, 82], Diabetes Reduction Assessment with ramipril and rosiglitazone Medication (DREAM) [83] and the Study TO Prevent NIDDM (STOP-NIDDM)
[10] studies the participants had none or minimal CVD. In the major $\mathrm{CV}$ outcomes trials, UKPDS [3], Kumamoto [84], PROactive [85], ACCORD [5], ADVANCE [7], VADT [4] and STENO-2 [44], the baseline glycemic control was in excess of $7.5 \%$. The ORIGIN trial represents a unique category of patients at an early stage of their disease possessing a high $\mathrm{CV}$ risk profile. The findings indicate that from a safety perspective, the ORIGIN trial demonstrates that basal insulin in the form of insulin glargine does not increase CVD events in persons with either pre-diabetes or newly diagnosed type 2 diabetes already at high $\mathrm{CV}$ risk. The extension sub-study, GRACE, provides additional data on the evolution of CIT, which concurs with the CV findings of the main study. A longer period of observation will be necessary to further clarify the truly long term safety of insulin glargine in these subjects, as illustrated by earlier studies in both type 1 (DCCT-EDIC) and type 2 diabetes (UKPDS). The fact that insulin glargine was able to reduce the fasting plasma glucose to $<5.3 \mathrm{mmol} / \mathrm{L}$ implied that the PPG was also controlled in the majority of subjects, which is important given the fact that PPG level is an independent risk factor for CVD.

From the perspective of disease management the early introduction of insulin, in an attempt to modify the course of the disease, offers a number of possibilities. The early use of intensive insulin therapy in persons with type 2 diabetes with an $\mathrm{HbA}_{1 \mathrm{c}}$ in the region of $9 \%$ or more has been repeatedly demonstrated to achieve near normal glycemia-both ambient glycemia and glucose variability-within weeks in most patients, and thereafter maintain this status for up to 1 or 2 years in up to $50 \%$ of subjects. This therapeutic approach improves both $\beta$-cell function and insulin sensitivity, inducing a remission, honeymoon phase of type 2 diabetes. However, with no further 
intervention this improvement slowly deteriorates over time. Inducing and maintaining near-normoglycemia is a subject of great interest with different strategies currently being explored. Liraglutide provided robust enhancement of $\beta$-cell function following intensive insulin therapy in early T2DM that was sustained over 48 weeks, but lost when therapy was stopped [86]. Other strategies include intermittent intensive insulin therapy (RESET IT, ClinicalTrials.gov NCT02192424) and the combination of exenatide and insulin (PREVAIL, ClinicalTrials.gov NCT02194595).

ORIGIN also included persons with pre-diabetes in whom it was demonstrated that disease progression was retarded on basal insulin therapy. As this involved a relatively small number of subjects, a longer-term evaluation is required. This trend persisted for approximately 3 years post-ORIGIN, as seen in the ORIGINALE trial [18]. Identification of the novel biomarkers involved may help to elucidate the impact of early insulin therapy on the progression of dysglycemia, CVD and death [87].

Early insulin treatment therefore presents an additional option for persons with type 2 diabetes, which is capable of restoring residual $\beta$-cell function in the short term, providing the basis for a better response to the different maintenance therapies presently available. This would be a departure from the current guidelines, but a justifiable one both from an efficacy and safety point of view. We therefore propose that there are specific thresholds at which insulin should be initiated: first, transiently to obtain initial glycemic control; and then later, both in early diabetes and subsequently in later-stage disease in combination with other anti-diabetic agents as glycemic control worsens (Fig. 2). In ORIGIN,

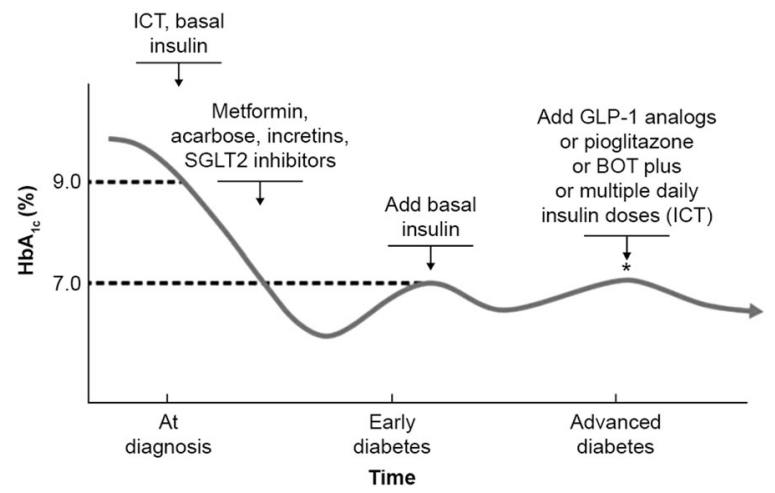

Fig. 2 A forward strategy for prevention of diabetes progression and diabetes-related complications. BOT basal-supported oral therapy, GLP-1 glucagon-like peptide 1, $H b A_{1 c}$ glycated hemoglobin, ICT intensified conventional therapy, SGLT2 sodium glucose co-transporter 2. Reprinted with permission from Markolf Hanefeld

insulin glargine as an early add-on treatment to metformin was associated with a low risk of hypoglycemia and only moderate weight gain. No effect on CV outcomes or all-cause mortality was shown for early insulin treatment compared with standard care after approximately 6 years of follow-up. However, the recent results suggest that early insulin attenuated the risk of microvascular outcomes only in participants with a baseline $\mathrm{HbA}_{1 \mathrm{c}}$ level $\geq 6.4 \%$ [79]. The ADA/EASD guidelines recommend an $\mathrm{HbA}_{1 \mathrm{c}} \leq 7 \%$ to reduce microvascular complications, with a more stringent goal of $<6.5 \%$ in selected individuals. This more stringent goal in selected individuals is in line with the findings from ORIGIN.

\section{ACKNOWLEDGMENTS}

Editorial support was provided by Lisa Swanson and Sandy Ong of Havas Life Medicom, Lisa Langley of Discovery London, and Tom Claus of PAREXEL, and funded by Sanofi. The study and article processing charges were also funded by Sanofi. The contents of this paper and opinions 
expressed within are those of the authors, and it was the decision of the authors to submit the manuscript for publication. The authors were responsible for the conception of the manuscript and contributed to the writing, including the critical review and editing of each draft, and approval of the final version for submission. All named authors meet the International Committee of Medical Journal Editors (ICMJE) criteria for authorship for this manuscript, take responsibility for the integrity of the work as a whole, and have given final approval for the version to be published.

Disclosures. Markolf Hanefeld has received speaker honoraria from Takeda, GlaxoSmithKline, Roche, Bayer, Lilly, and Sanofi-Aventis, and advisory board honoraria from Sanofi-Aventis, Takeda, Bristol-Myers Squibb, and GlaxoSmithKline. David Owens has received grants from Boehringer Ingelheim, Roche Diagnostics, NovoNordisk, and Sanofi for lectures and/or involvement in advisory boards. Louis Monnier and Oliver Schnell have nothing to disclose.

Compliance with Ethical Guidelines. This article is based on previously conducted studies and does not involve any new studies of human or animal subjects performed by the authors.

Open Access. This article is distributed under the terms of the Creative Commons Attribution-NonCommercial 4.0 International License (http://creativecommons.org/licenses/ by-nc/4.0/), which permits any noncommercial use, distribution, and reproduction in any medium, provided you give appropriate credit to the original author(s) and the source, provide a link to the Creative Commons license, and indicate if changes were made.

\section{REFERENCES}

1. International Diabetes Federation. Diabetes atlas. 5th edition. 2011. https://www.idf.org/sites/ default/files/21991_diabAtlas_5thEd.pdf. Accessed 23 Nov 2012.

2. Chen L, Magliano DJ, Zimmet PZ. The worldwide epidemiology of type 2 diabetes mellitus-present and future perspectives. Nat Rev Endocrinol. 2012;8:228-36.

3. UK Prospective Diabetes Study (UKPDS) Group. Effect of intensive blood-glucose control with metformin on complications in overweight patients with type 2 diabetes (UKPDS 34). Lancet. 1998;352:854-65.

4. Duckworth W, Abraira C, Moritz T, et al. Glucose control and vascular complications in veterans with type 2 diabetes. N Engl J Med. 2009;360:129-39.

5. Gerstein HC, Miller ME, Byington RP, et al. Effects of intensive glucose lowering in type 2 diabetes. N Engl J Med. 2008;358:2545-59.

6. Holman RR, Paul SK, Bethel MA, Matthews DR, Neil HA. 10-year follow-up of intensive glucose control in type 2 diabetes. N Engl J Med. 2008;359:1577-89.

7. Patel A, MacMahon S, Chalmers J, et al. Intensive blood glucose control and vascular outcomes in patients with type 2 diabetes. $\mathrm{N}$ Engl J Med. 2008;358:2560-72.

8. Lindstrom J, Ilanne-Parikka $\mathrm{P}$, Peltonen $\mathrm{M}$, et al. Sustained reduction in the incidence of type 2 diabetes by lifestyle intervention: follow-up of the Finnish Diabetes Prevention Study. Lancet. 2006;368:1673-9.

9. Knowler WC, Fowler SE, Hamman RF, et al. 10-year follow-up of diabetes incidence and weight loss in the Diabetes Prevention Program Outcomes Study. Lancet. 2009;374:1677-86.

10. Chiasson JL, Josse RG, Gomis R, Hanefeld M, Karasik A, Laakso M. Acarbose for prevention of type 2 diabetes mellitus: the STOP-NIDDM randomised trial. Lancet. 2002;359:2072-7.

11. Kahn SE, Haffner SM, Heise MA, et al. Glycemic durability of rosiglitazone, metformin, or glyburide monotherapy. N Engl J Med. 2006;355:2427-43.

12. American Diabetes Association. (7) Approaches to glycemic treatment. Diabetes Care. 2015;38(Suppl):S41-8. 
13. Butler AE, Janson J, Bonner-Weir S, Ritzel R, Rizza RA, Butler PC. Beta-cell deficit and increased beta-cell apoptosis in humans with type 2 diabetes. Diabetes. 2003;52:102-10.

14. Ritzel RA, Butler AE, Rizza RA, Veldhuis JD, Butler PC. Relationship between beta-cell mass and fasting blood glucose concentration in humans. Diabetes Care. 2006;29:717-8.

15. UK Prospective Diabetes Study Group. U.K. prospective diabetes study 16. Overview of 6 years' therapy of type II diabetes: a progressive disease. Diabetes. 1995;44:1249-58.

16. Tripathy D, Carlsson M, Almgren P, et al. Insulin secretion and insulin sensitivity in relation to glucose tolerance: lessons from the Botnia Study. Diabetes. 2000;49:975-80.

17. ORIGIN Trial Investigators, Gerstein HC, Bosch J, et al. Basal insulin and cardiovascular and other outcomes in dysglycemia. $\mathrm{N}$ Engl J Med. 2012;367:319-28.

18. ORIGIN Trial Investigators. Cardiovascular and other outcomes postintervention with insulin glargine and omega-3 fatty acids (ORIGINALE). Diabetes Care. 2015. pii: dc151676. [Epub ahead of print].

19. Ceriello A, Esposito K, Ihnat M, Thorpe J, Giugliano D. Effect of acute hyperglycaemia, long-term glycaemic control and insulin on endothelial dysfunction and inflammation in type 1 diabetic patients with different characteristics. Diabetes Med. 2010;27:911-7.

20. Monnier L, Colette C, Dunseath GJ, Owens DR. The loss of postprandial glycemic control precedes stepwise deterioration of fasting with worsening diabetes. Diabetes Care. 2007;30:263-9.

21. Meier JJ, Breuer TG, Bonadonna RC, et al. Pancreatic diabetes manifests when beta cell area declines by approximately $65 \%$ in humans. Diabetologia. 2012;55:1346-54.

22. Weyer C, Tataranni PA, Bogardus C, Pratley RE. Insulin resistance and insulin secretory dysfunction are independent predictors of worsening of glucose tolerance during each stage of type 2 diabetes development. Diabetes Care. 2001;24:89-94.

23. Mitrakou A, Kelley D, Mokan M, et al. Role of reduced suppression of glucose production and diminished early insulin release in impaired glucose tolerance. N Engl J Med. 1992;326:22-9.

24. Halban PA, Polonsky KS, Bowden DW, et al. Beta-cell failure in type 2 diabetes: postulated mechanisms and prospects for prevention and treatment. Diabetes Care. 2014;37:1751-8.

25. Poitout V, Robertson RP. Glucolipotoxicity: fuel excess and beta-cell dysfunction. Endocr Rev. 2008;29:351-66.

26. Gleason CE, Gonzalez M, Harmon JS, Robertson RP. Determinants of glucose toxicity and its reversibility in the pancreatic islet beta-cell line, HIT-T15. Am J Physiol Endocrinol Metab. 2000;279:E997-1002.

27. Man ZW, Zhu M, Noma Y, et al. Impaired beta-cell function and deposition of fat droplets in the pancreas as a consequence of hypertriglyceridemia in OLETF rat, a model of spontaneous NIDDM. Diabetes. 1997;46:1718-24.

28. Scognamiglio R, Negut C, de Kreutzenberg SV, Tiengo A, Avogaro A. Effects of different insulin regimes on postprandial myocardial perfusion defects in type 2 diabetic patients. Diabetes Care. 2006;29:95-100.

29. Esposito K, Giugliano D, Nappo F, Marfella R. Regression of carotid atherosclerosis by control of postprandial hyperglycemia in type 2 diabetes mellitus. Circulation. 2004;110:214-9.

30. Chen A, Huang Z, Wan X, et al. Attitudes toward diabetes affect maintenance of drug-free remission in patients with newly diagnosed type 2 diabetes after short-term continuous subcutaneous insulin infusion treatment. Diabetes Care. 2012;35:474-81.

31. Drzewoski J, Kasznicki J, Trojanowski Z. The role of "metabolic memory" in the natural history of diabetes mellitus. Pol Arch Med Wewn. 2009;119:493-500.

32. Monnier L, Colette C, Mas E, et al. Regulation of oxidative stress by glycaemic control: evidence for an independent inhibitory effect of insulin therapy. Diabetologia. 2010;3:562-71.

33. Tian J, Wang J, Li Y, et al. Endothelial function in patients with newly diagnosed type 2 diabetes receiving early intensive insulin therapy. Am J Hypertens. 2012;25:1242-8.

34. Chen H, Ren A, Hu S, Mo W, Xin X, Jia W. The significance of tumor necrosis factor-alpha in newly diagnosed type 2 diabetic patients by transient intensive insulin treatment. Diabetes Res Clin Pract. 2007;75:327-32.

35. Brownlee M. Biochemistry and molecular cell biology of diabetic complications. Nature. 2001;414:813-20.

36. Li F, Zhao T, Wen X. Changes in serum adiponectin concentrations and endothelial function after 
intensive insulin treatment in people with newly diagnosed type 2 diabetes: a pilot study. Diabetes Res Clin Pract. 2011;94:186-92.

37. Dandona P, Chaudhuri A, Ghanim H, Mohanty P. Use of insulin to improve glycemic control in diabetes mellitus. Cardiovasc Drugs Ther. 2008;22:241-51.

38. Rahier J, Guiot Y, Goebbels RM, Sempoux C, Henquin JC. Pancreatic beta-cell mass in European subjects with type 2 diabetes. Diabetes Obes Metab. 2008;10(Suppl 4):32-42.

39. Del Prato S. Role of glucotoxicity and lipotoxicity in the pathophysiology of type 2 diabetes mellitus and emerging treatment strategies. Diabetes Med. 2009;26:1185-92.

40. Ceriello A, Ihnat MA, Thorpe JE. Clinical review 2: the "metabolic memory": is more than just tight glucose control necessary to prevent diabetic complications? J Clin Endocrinol Metab. 2009;94:410-5.

41. Kramer CK, Zinman B, Retnakaran R. Short-term intensive insulin therapy in type 2 diabetes mellitus: a systematic review and meta-analysis. Lancet Diabetes Endocrinol. 2013;1:28-34.

42. Weng J, Li Y, Xu W, et al. Effect of intensive insulin therapy on beta-cell function and glycaemic control in patients with newly diagnosed type 2 diabetes: a multicentre randomised parallel-group trial. Lancet. 2008;371:1753-60.

43. Chen HS, Wu TE, Jap TS, Hsiao LC, Lee SH, Lin HD. Beneficial effects of insulin on glycemic control and beta-cell function in newly diagnosed type 2 diabetes with severe hyperglycemia after short-term intensive insulin therapy. Diabetes Care. 2008;31:1927-32.

44. Gaede P, Lund-Andersen H, Parving HH, Pedersen O. Effect of a multifactorial intervention on mortality in type 2 diabetes. $\mathrm{N}$ Engl J Med. 2008;358:580-91.

45. Harrison LB, Adams-Huet B, Raskin P, Lingvay I. beta-Cell function preservation after 3.5 years of intensive diabetes therapy. Diabetes Care. 2012;35:1406-12.

46. $\mathrm{Li} \mathrm{Y}, \mathrm{Xu} \mathrm{W}$, Liao $\mathrm{Z}$, et al. Induction of long-term glycemic control in newly diagnosed type 2 diabetic patients is associated with improvement of beta-cell function. Diabetes Care. 2004;27:2597-602.

47. Lingvay I, Legendre JL, Kaloyanova PF, Zhang S, Adams-Huet B, Raskin P. Insulin-based versus triple oral therapy for newly diagnosed type 2 diabetes: which is better? Diabetes Care. 2009;32:1789-95.

48. Mu PW, Chen YM, Lu HY, et al. Effects of a combination of oral anti-diabetes drugs with basal insulin therapy on beta-cell function and glycaemic control in patients with newly diagnosed type 2 diabetes. Diabetes Metab Res Rev. 2012;28:236-40.

49. Owens DR, Matfin G, Monnier L. Basal insulin analogues in the management of diabetes mellitus: what progress have we made? Diabetes Metab Res Rev. 2014;30:104-19.

50. Pistrosch F, Kohler C, Schaper F, Landgraf W, Forst T, Hanefeld M. Effects of insulin glargine versus metformin on glycemic variability, microvascular and beta-cell function in early type 2 diabetes. Acta Diabetol. 2013;50:587-95.

51. Retnakaran R, Drucker DJ. Intensive insulin therapy in newly diagnosed type 2 diabetes. Lancet. 2008;371:1725-6.

52. $\mathrm{Xu} \mathrm{W,} \mathrm{Li} \mathrm{YB,} \mathrm{Deng} \mathrm{WP,} \mathrm{Hao} \mathrm{YT,} \mathrm{Weng} \mathrm{JP.}$ Remission of hyperglycemia following intensive insulin therapy in newly diagnosed type 2 diabetic patients: a long-term follow-up study. Chin Med J (Engl). 2009;122:2554-9.

53. Chon S, Oh S, Kim SW, Kim JW, Kim YS, Woo JT. The effect of early insulin therapy on pancreatic beta-cell function and long-term glycemic control in newly diagnosed type 2 diabetic patients. Korean J Intern Med. 2010;25:273-81.

54. Zeng $\mathrm{L}$, Lu $\mathrm{H}$, Deng $\mathrm{H}, \mathrm{Mu} \mathrm{P,} \mathrm{Li} \mathrm{X}$, Wang $\mathrm{M}$. Noninferiority effects on glycemic control and beta-cell function improvement in newly diagnosed type 2 diabetes patients: basal insulin monotherapy versus continuous subcutaneous insulin infusion treatment. Diabetes Technol Ther. 2012;14:35-42.

55. Riddle MC, Rosenstock J, Gerich J. The treat-to-target trial: randomized addition of glargine or human NPH insulin to oral therapy of type 2 diabetic patients. Diabetes Care. 2003;26:3080-6.

56. Forst T, Larbig M, Hohberg C, et al. Adding insulin glargine vs. NPH insulin to metformin results in a more efficient postprandial beta-cell protection in individuals with type 2 diabetes. Diabetes Obes Metab. 2010;12:437-41.

57. Opsteen C, Qi Y, Zinman B, Retnakaran R. Effect of short-term intensive insulin therapy on quality of life in type 2 diabetes. J Eval Clin Pract. 2012;18:256-61.

58. Hanefeld M, Fleischmann H, Landgraf W, Pistrosch F. EARLY study: early basal insulin therapy under 
real-life conditions in type 2 diabetics. Diabetes Stoffw Herz. 2012;21:91-7.

59. Hanefeld M, Fleischmann H, Schiffhorst G, Bramlage P. Predictors of response to early basal insulin treatment in patients with type 2 diabetesthe EARLY experience. Diabetes Technol Ther. 2014;16:241-6.

60. Fonseca V, Gill J, Zhou R, Leahy J. An analysis of early insulin glargine added to metformin with or without sulfonylurea: impact on glycaemic control and hypoglycaemia. Diabetes Obes Metab. 2011;13:814-22.

61. Pennartz C, Schenker N, Menge BA, Schmidt WE, Nauck MA, Meier JJ. Chronic reduction of fasting glycemia with insulin glargine improves firstand second-phase insulin secretion in patients with type 2 diabetes. Diabetes Care. 2011;34: 2048-53.

62. Bartnik M, Ryden L, Ferrari R, et al. The prevalence of abnormal glucose regulation in patients with coronary artery disease across Europe. The Euro Heart Survey on diabetes and the heart. Eur Heart J. 2004;25:1880-90.

63. Ford ES. Trends in the risk for coronary heart disease among adults with diagnosed diabetes in the U.S.: findings from the National Health and Nutrition Examination Survey, 1999-2008. Diabetes Care. 2011;34:1337-43.

64. Boussageon R, Bejan-Angoulvant T, Saadatian-Elahi $M$, et al. Effect of intensive glucose lowering treatment on all cause mortality, cardiovascular death, and microvascular events in type 2 diabetes: meta-analysis of randomised controlled trials. BMJ. 2011;343:d4169.

65. Hemmingsen B, Lund SS, Gluud C, et al. Targeting intensive glycaemic control versus targeting conventional glycaemic control for type 2 diabetes mellitus. Cochrane Database Syst Rev. 2013;11:CD008143.

66. Ray KK, Seshasai SR, Wijesuriya S, et al. Effect of intensive control of glucose on cardiovascular outcomes and death in patients with diabetes mellitus: a meta-analysis of randomised controlled trials. Lancet. 2009;373:1765-72.

67. Centers for Medicare and Medicaid Services (CMS), Department of Health and Human Services (HHS). Patient Protection and Affordable Care Act; exchange functions: standards for navigators and non-navigator assistance personnel; consumer assistance tools and programs of an exchange and certified application counselors. Final rule. Fed Regist. 2013;78:42823-62.
68. Nathan DM, Cleary PA, Backlund JY, et al. Intensive diabetes treatment and cardiovascular disease in patients with type 1 diabetes. $\mathrm{N}$ Engl J Med. 2005;353:2643-53.

69. UK Prospective Diabetes Study (UKPDS) Group. Intensive blood-glucose control with sulphonylureas or insulin compared with conventional treatment and risk of complications in patients with type 2 diabetes (UKPDS 33). Lancet. 1998;352:837-53.

70. Gaede P, Vedel P, Larsen N, Jensen GV, Parving HH, Pedersen O. Multifactorial intervention and cardiovascular disease in patients with type 2 diabetes. N Engl J Med. 2003;348:383-93.

71. Gerstein H, Yusuf S, Riddle MC, Ryden L, Bosch J. Rationale, design, and baseline characteristics for a large international trial of cardiovascular disease prevention in people with dysglycemia: the ORIGIN trial (outcome reduction with an initial glargine intervention). Am Heart J. 2008;155(26-32):32.

72. Anselmino M, Malmberg K, Ohrvik J, Ryden L. Evidence-based medication and revascularization: powerful tools in the management of patients with diabetes and coronary artery disease: a report from the Euro Heart Survey on diabetes and the heart. Eur J Cardiovasc Prev Rehabil. 2008;15:216-23.

73. Mellbin LG, Malmberg K, Norhammar A, Wedel H, Ryden L. Prognostic implications of glucose-lowering treatment in patients with acute myocardial infarction and diabetes: experiences from an extended follow-up of the Diabetes Mellitus Insulin-Glucose Infusion in Acute Myocardial Infarction (DIGAMI) 2 Study. Diabetologia. 2011;54:1308-17.

74. Lonn EM, Bosch J, Diaz R, et al. Effect of insulin glargine and n-3FA on carotid intima-media thickness in people with dysglycemia at high risk for cardiovascular events: the glucose reduction and atherosclerosis continuing evaluation study (ORIGIN-GRACE). Diabetes Care. 2013;36:2466-74.

75. ORIGIN Trial Investigators. Characteristics associated with maintenance of mean A1C $<6.5 \%$ in people with dysglycemia in the ORIGIN trial. Diabetes Care. 2013;36:2915-22.

76. Mellbin LG, Ryden L, Riddle MC, et al. Does hypoglycaemia increase the risk of cardiovascular events? A report from the ORIGIN trial. Eur Heart J. 2013;34:3137-44.

77. Hanefeld M, Koehler C, Hoffmann C, Wilhelm K, Kamke W, Gerstein H. Effect of targeting normal fasting glucose levels with basal insulin glargine 
on glycaemic variability and risk of hypoglycaemia: a randomized, controlled study in patients with early type 2 diabetes. Diabetes Med. 2010;27:175-80.

78. Holman RR, Farmer AJ, Davies MJ, et al. Three-year efficacy of complex insulin regimens in type 2 diabetes. N Engl J Med. 2009;361:1736-47.

79. Gilbert RE, Mann JF, Hanefeld M, et al. Basal insulin glargine and microvascular outcomes in dysglycaemic individuals: results of the Outcome Reduction with an Initial Glargine Intervention (ORIGIN) trial. Diabetologia. 2014;57:1325-31.

80. Holman RR, Haffner SM, McMurray JJ, et al. Effect of nateglinide on the incidence of diabetes and cardiovascular events. $\mathrm{N}$ Engl $\mathrm{J}$ Med. 2010;362:1463-76.

81. McMurray JJ, Holman RR, Haffner SM, et al. Effect of valsartan on the incidence of diabetes and cardiovascular events. $\mathrm{N}$ Engl J Med. 2010;362:1477-90.

82. Knowler WC, Barrett-Connor E, Fowler SE, et al. Reduction in the incidence of type 2 diabetes with lifestyle intervention or metformin. $\mathrm{N}$ Engl J Med. 2002;346:393-403.
83. Gerstein HC, Yusuf S, Bosch J, et al. Effect of rosiglitazone on the frequency of diabetes in patients with impaired glucose tolerance or impaired fasting glucose: a randomised controlled trial. Lancet. 2006;368:1096-105.

84. Ohkubo Y, Kishikawa H, Araki E, et al. Intensive insulin therapy prevents the progression of diabetic microvascular complications in Japanese patients with non-insulin-dependent diabetes mellitus: a randomized prospective 6-year study. Diabetes Res Clin Pract. 1995;28:103-17.

85. Dormandy JA, Charbonnel B, Eckland DJ, et al. Secondary prevention of macrovascular events in patients with type 2 diabetes in the PROactive Study (PROspective pioglitAzone Clinical Trial In macroVascular Events): a randomised controlled trial. Lancet. 2005;366:1279-89.

86. Retnakaran R, Kramer CK, Choi H, Swaminathan B, Zinman B. Liraglutide and the preservation of pancreatic beta-cell function in early type 2 diabetes: the LIBRA trial. Diabetes Care. 2014;37:3270-8.

87. Gerstein HC, Pare G, McQueen MJ, et al. Identifying novel biomarkers for cardiovascular events or death in people with dysglycemia. Circulation. 2015;132:2297-304. 